\title{
Radiographic Anatomy and Calcaneal Width Measurements on Tangential View
}

\author{
Q Wang, Y Zhang, X Wu, Q Meng
}

\begin{abstract}
Aim: To investigate the radiographic anatomical characters of the bones in the fractured calcaneus by using tangential $X$-rays.

Methods: Fifty-seven patients (114 sides) with normal calcaneus and thirty patients (42 sides) with fractured calcaneus were radiographed along the line connecting the midpoint of the $4^{\text {th }}$ and $5^{\text {th }}$ metatarsal heads with the lateral margin of the corpus calcanei. The anatomical characters of the calcaneus on the tangential X-ray views were analysed, including radius and fractal geometry.

Results: On a tangential X-ray view of the fractured calcaneus, the projection of sustentaculum tali resembled a duck beak, which was just under the middle facet of the talocalcaneal joint. The corpus calcanei appeared oval, which was just under the talocalcaneal joint articular surface. The lateral calcaneal wall did not exceed the vertical line extending from medial of the lateral malleolar fossa (the Z-W line). From the scan picture, the fractured calcaneus seemed to be widened as its lateral wall crossed the Z-W line. The longitudinal axis of this oval-shaped projection was $3.52 \pm 0.41 \mathrm{~cm}(\mathrm{a})$, the horizontal axis was $2.56 \pm 0.28 \mathrm{~cm}(\mathrm{~b})$, and the a/b ratio was $1.40 \pm 0.11$. In the normal calcaneus, the $a / b$ ratio is higher than 1.40 and the differences of the values in these two groups were significant. Therefore, the a/b ratio of the calcaneal oval-shaped projection can be used to evaluate the degree of its deformity after fracture.

Conclusion: These results demonstrated that the tangential X-ray view of the calcaneus can be used to evaluate its radiographic anatomy and to measure the radii of the oval-shaped corpus calcanei.
\end{abstract}

Keywords: Anatomy, calcaneus, fracture, tangential view of the calcaneus width, X-ray

\section{Anatomía Radiológica y Mediciones Tangenciales del Ancho del Calcáneo}

Q Wang, Y Zhang, X Wu, Q Meng

\begin{abstract}
RESUMEN
Objetivo: Investigar las características anátomo-radiográficas de los huesos en el calcáneo fracturado, mediante el uso de rayos $x$ tangenciales.

Métodos: Cincuenta y siete pacientes (114 lados) con calcáneo normal y treinta pacientes (42 lados) con fractura del calcáneo fueron radiografiados a lo largo de la línea que une el punto medio de la 4ta y 5ta cabezas metatarsianas con el margen lateral del cuerpo calcáneo (corpus calcanei). Se analizaron los rasgos anatómicos del calcáneo observados en los rayos $x$ tangenciales de rayos $x$, incluyendo el radio y la geometría fractal.

Resultados: En la vista tangencial de la radiografia del calcáneo fracturado, la proyección del sustentaculum tali, se asemejó a un pico de pato, justamente debajo de la cara media de la ar-
\end{abstract}

From: Department of Orthopaedic Trauma, Third Hospital, Hebei Medical

University, Shijiazhuang 050051, China.
Correspondence: Dr Q Wang, Department of Orthopaedic Trauma, Third Hospital, Hebei Medical University, 139. Ziqiang Road, Shijiazhuang, Hebei province, 050051 China. Fax: +86031188602065 , Email: qingxianwang2014@163.com 
ticulación talocalcáne a. El cuerpo calcáneo de apariencia oval, se hallaba justo debajo de la superficie articular de la articulación talocalcánea. La pared lateral calcánea no excedía la línea vertical que se extiende desde la fosa maleolar medial a la lateral (línea Z-W). En la imagen escaneada, el calcáneo fracturado parecía haberse anchado cuando su pared lateral cruzó la línea $Z-W$. El eje longitudinal de esta proyección ovalada medía $3.52 \pm 0.41 \mathrm{~cm}($ a), el eje horizontal medía $2.56 \pm 0.28 \mathrm{~cm}$ (b), y el cociente de a/b fue $1.40 \pm 0.11$. En el calcáneo normal, el cociente a/b es mayor de 1.40, y las diferencias de los valores en estos dos grupos fueron significativas. Por lo tanto, el cociente a/b de la proyección ovalada del calcáneo, puede usarse para evaluar su grado de deformidad después de la fractura.

Conclusión: Estos resultados demostraron que la radiografía tangencial del calcáneo puede usarse para evaluar su anatomía radiográfica y medir los radios del cuerpo calcáneo ovalado.

Palabras claves: Anatomía, calcáneo, fractura, vista tangencial del ancho del calcáneo, rayos X

West Indian Med J 2017; 66 (2): 198

\section{INTRODUCTION}

Along with the rapid development of the construction and transportation industries, the number of patients with calcaneal fractures has been increasing annually (1). Conservative treatment has been widely applied for displaced calcaneal fractures. However, long-term followup studies have shown that conservative treatment cannot reduce the fractures and may, in fact, result in a relatively high morbidity due to the abnormal widening of the calcaneus $(2,3)$. Therefore, most scholars have advocated open reduction and internal fixation of displaced intraarticular calcaneal fractures. The axial fluoroscopic view is routinely used to identify the recovery of the calcaneal width (4). However, because the surgeon often holds the patient's ankle during the X-ray, they both are exposed to a large dose of radiation. Moreover, the axial view varies with the different projection angles, and this affects the objective evaluation of the calcaneal width during surgery (5). Therefore, we designed a tangential X-ray projection of the calcaneus, investigated its radiographic anatomy on tangential view, and identified the relationship between the lateral calcaneal wall and the anatomical markers.

\section{Clinical data}

General data: Between May 2009 and April 2011, we carried out tangential X-rays of the calcaneus in 57 patients with normal and 30 patients (42 sides) with fractured calcanei. The radiographic anatomy of the bone was observed and the method of measuring its width was investigated. Among 57 cases with normal calcancei, there were 40 males and 17 females, with an average age of 41.7 years (range 32-54 years).

All of the participants agreed to receive the radiation and signed the informed consent.

\section{SUBJECTS AND METHODS Methods for the X-ray examination}

A Siemens Axiom Aristos FX Radiography system was used in the current study. The X-ray projection was di-rected along the line connecting the midpoint of the fourth and fifth metatarsal heads with the lateral margin of the corpus calcanei. The internal rotation of the foot was about $15-20^{\circ}$ (Fig. 1). The exposure conditions were $71.5 \mathrm{kv}$ and $4.0 \mathrm{mAs}$. A scale was placed outside the middle of the calcaneus, parallel to the examination bed. The gonads and other sensitive parts were protected with lead aprons.

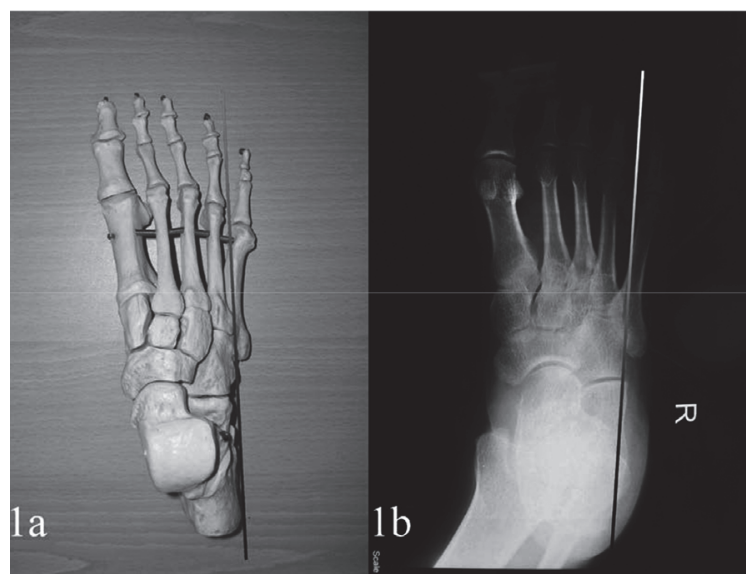

Fig. 1: The direction of the X-ray projection on the tangential view of the calcaneus. 


\section{RESULTS}

In order to measure the parameters in the X-ray pictures, lineation and measurements of the calcaneus were carried out. The normal calcaneus appeared as a typical symmetrical oval on tangential X-rays (Fig. 2). The upper arc (CD in Fig. 2) was the smooth articular surface of the posterior talocalcaneal joint; the arc (DE in Fig. 2) was the articular surface of the middle talocalcaneal joint. Sustentaculum tali with a duckbilled shape (S in Fig. 2) were located medially to the oval. The lateral wall of the calcaneus was continuous and smooth, and did not exceed the $\mathrm{Z}$ line, which was vertical to the medial side of the lateral malleolar fossa (f). The inferolateral protrusion from the oval was the lateral process of the calcaneal tuberosity $(\mathrm{g})$.

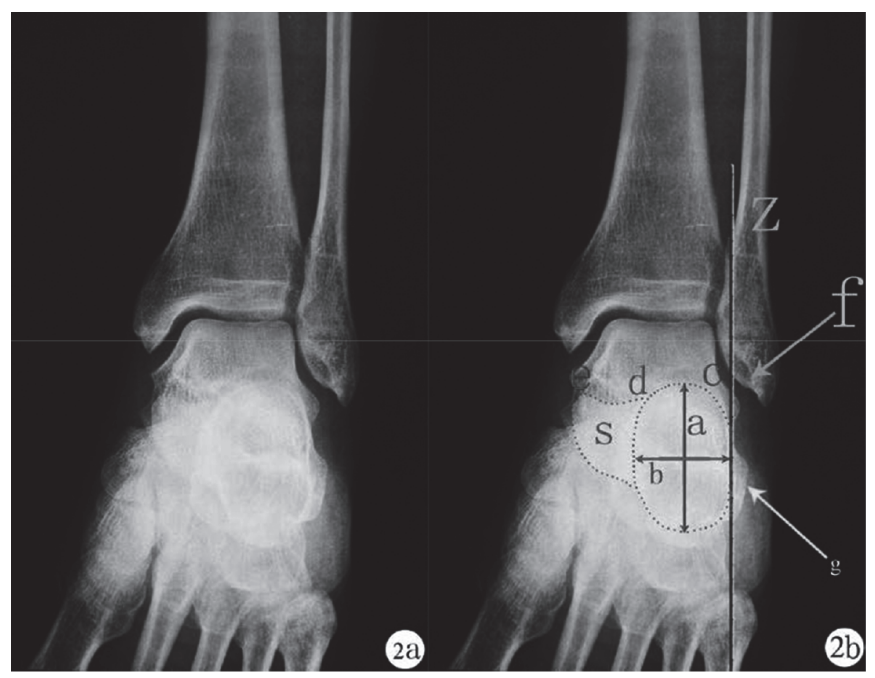

Fig. 2, 2a: X-ray of the tangential view of a normal calcaneus;

2b: Lineation and measurement of the tangential X-ray of the same calcaneus.

The computed tomography $(\mathrm{CT})$ scan revealed that the lateral calcaneal margin exceeded the vertical line to the medial side of the lateral malleolar fossa (f) in the fractured calcaneus [with a widened calcaneus] (Fig.3).

Once the lateral calcaneal margin exceeded this vertical line, it indicated that the bone was already widened. Therefore, this vertical line was the demarcation to indicate whether widening has occurred. We defined this vertical line as Zhang Yingze-Wang Qingxian's line, inshort, the Z-W line. The mean longitudinal axis (a) of the oval-shaped calcaneal projection was 3.52 $\pm 0.41 \mathrm{~cm}$, the mean horizontal axis (b) was $2.56 \pm 0.28$ $\mathrm{cm}$ and the $\mathrm{a} / \mathrm{b}$ ratio was $1.40 \pm 0.11$ in the fractured calcaneus.

When the calcaneal fracture was intra-articular and involved the posterior talocalcaneal joint, unevenness or breakage was observed in the cd arc, representing the posterior articular surface. When the lateral wall was fractured, breakage and protrusion of the lateral margin of the oval-shape could be observed on the tangential views (Fig. 3F1). The semi-coronal CT scan of the same fractured calcaneus also showed obvious fracture lines and the lateral protrusion of the lateral wall (Fig. 3F2). Therefore, the X-ray findings of the calcaneal fracture on tangential views were completely the same as the results of the semi-coronal CT scan of the fractured bone. Because the fractured calcaneus became widened (increased $b$ value), and its height decreased (reduced $a$ value), the $a / b$ ratio was decreased significantly in the fractured calcaneus. Therefore, the $\mathrm{a} / \mathrm{b}$ ratio was considered to be effective in evaluating the calcaneal deformity, guiding therapy and assessing the outcome.

\section{DISCUSSION}

The calcaneus is a nearly rectangular bone located beneath the talus. Its corpulent rear is called the corpus calcanei and the posterior protrusion of its body is called

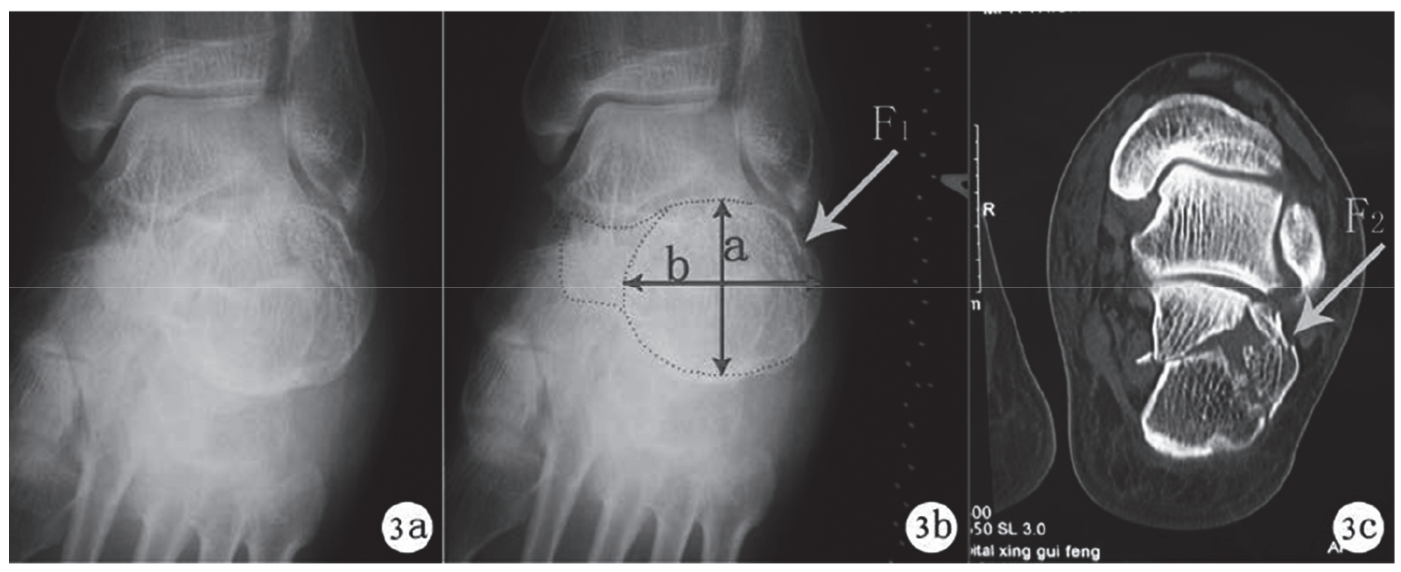

Fig. 3. 3a: The tangential view of a fractured calcaneus; 3b: Lineation and measurement of the tangential X-ray of the fractured calcaneus; $3 \mathrm{c}$ : Semi-coronal CT scan of the facies articularis calcanearis posterior. 
the calcaneal tuberosity. The inferolateral part of the calcaneus is the lateral process of the calcaneal tuberosity and its inferomedial part is the medial process of the calcaneal tuberosity. The calcaneus has six articular surfaces, the superior, inferior, anterior, posterior, medial and lateral surfaces. The middle of the superior surface presents an oval prominence called the posterior articular surface. Superomedially from the calcaneus, there is a flat process called the sustentaculum tali. The depression of the superior surface, known as the middle articular surface articulates with the middle calcaneal articular surface of the caput tali. A small articular surface in the anterior part of the superior calcaneal surface is called the anterior surface and it articulates with the anterior calcaneal articular surface of the caput tali. The lateral surface of the calcaneus is wide and smooth. A nodule, called the trochlear process, is located in the anterior part. An oblique groove, called the groove for the tendon of the peroneus longus, is located posteroinferiorly from this process. The direction of the X-ray projection in the current study was along the line connecting the midpoints of the fourth and fifth metatarsal heads and the lateral margin of the corpus calcanei. Internal rotation of the foot was about $15-20^{\circ}$ at the moment when the ankle was in slight plantar flexion. This is the so-called tangential view of the calcaneus (Fig.1).

Calcaneal fractures account for approximately $2 \%$ of all fractures and they accompany $60 \%$ of tarsal bone injuries. Furthermore, $80-90 \%$ of the patients are adult males and some of them become disabled as a result of the injury (1), which exerts a significant impact on society and on family. The main cause of pain after calcaneal fractures include: widening of the calcaneus, loss of its height, a stepped displacement in the posterior articular surface exceeding $3 \mathrm{~mm}$, varus or valgus deformity of the calcaneus and changes in the Böhler or Gissan angles. Therefore, in order to achieve an ideal outcome, one of the therapeutic targets in calcaneal fractures is to correct the widening deformity of the calcaneus and to prevent the tenosynovitis of the long and short-peroneal tendons. Many follow-up studies have shown that tenosynovitis of the long and short-peroneal tendons may be caused by the friction between the protruded lateral wall of the calcaneus and the long and short-peroneal tendons and tendon sheaths if the width of the calcaneus cannot be restored. The tenosynovitis may cause intractable pain in the inferior part of the lateral malleolus. In clinical practice, this is referred to as lateral impinge- ment syndrome. At this point, patients have to undergo resection of the calcaneal lateral bony process and decompression of the peroneal tendon sheath (5-8).

Measuring the calcaneal width after fractures is, therefore, a very important task. Xicheng et al performed measurements on the bone and, in vivo, by using CT scans and reported data about the calcaneal width. However, their method is too complicated for surgeons and, additionally, it is affected by the scales of the X-ray films and CT images. Moreover, the conversion process is complicated. The axial fluoroscopic view was commonly used to observe and measure the calcaneal width during surgery, and the surgeon has to hold the patient's ankle, which results in extensive exposure to radiation. Moreover, the variation of the axial views is noticeable according to the different X-ray projection angles and various angles of ankle dorsiflexion, which affect the objective intra-operative evaluation of the calcaneal width. Additionally, the patient has to suffer tremendous pain, due to the required ankle dorsiflexion before and after surgery. When obtaining the tangential view of the calcaneus, the patient is required to be in a resting position with only mild ankle plantar flexion. The surgeon can leave the operating room during fluoroscopy to avoid irradiation. In addition, the patient can be relieved from the pain caused by ankle dorsiflexion during the examination. Moreover, because the ankle is in a resting position, it does not move, ensuring excellent reproducibility of the images. Hence, this technique can accurately identify whether the width of the calcaneus is restored or not. Because the projection angle and the direction can be adjusted flexibly by the C-arm machine, the tangential Xray view of the calcaneus can be easily obtained during surgery (Fig. 4).

We used the tangential calcaneal view to measure its width. In this approach, the measurement is not affected by the scale of the X-ray film. The Z-W line is the demarcation that is used to determine whether the calcaneus is widened or not. This technique is accurate, easy to apply, has excellent reproducibility, and it can be used to compare pre- and postoperative outcomes. In addition, the $a / b$ ratio can be used to quantitatively evaluate calcaneal deformities, a new indicator of deformities after calcaneal fractures.

Both of the two methods for the evaluation of calcaneal fracture were effective. The anatomical landmarks can be used as qualitative indicators, and the measurements of width can be used as quantitative 


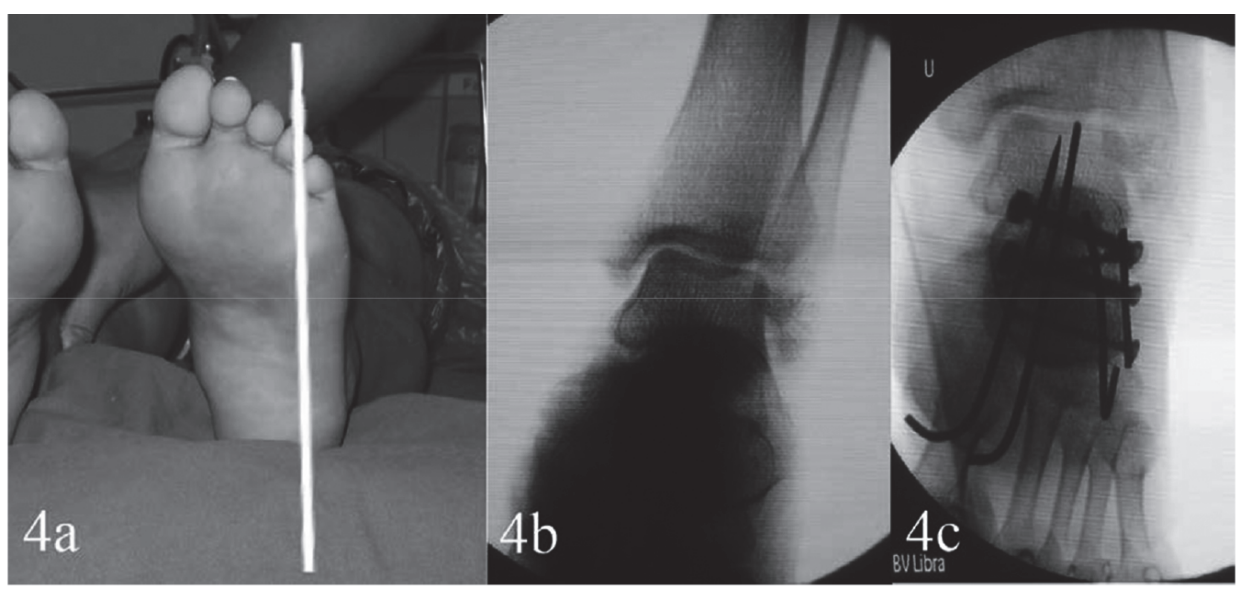

Fig. 4. 4a: Direction of the X-ray projection for the tangential view of the calcaneus; 4b: The tangential X-ray of the calcaneus in a fracture before surgery; $4 \mathrm{c}$ : The tangential X-ray of the same calcaneus after surgery.

indicators. The former one is suitable for analysis of small-size samples, and the latter one is suitable for analysis of large-size samples. Based on the small sample size in this study, we could not conclude which one is better. A larger sample size should be initiated for further investigation.

\section{REFERENCES}

1. Mitchell MJ, McKinley JC, Robinson CM. The epidemiology of calcaneal fractures. Foot (Edinb) 19 2009; 19: 197-200.

2. Sanders R, Vaupel ZM, Erdogan M, Downes K. Operative treatment of displaced intraarticular calcaneal fractures: long-term (10-20 Years) results in 108 fractures using a prognostic CT classification. J Orthop Trauma 2014; 28: 551-63.

3. Agren PH, Mukka S, Tullberg T, Wretenberg P, Sayed-Noor AS. Factors affecting long-term treatment results of displaced intraarticular calcaneal fractures: a post hoc analysis of a prospective, randomized, controlled multicenter trial. J Orthop Trauma 2014; 28: $564-8$.

4. Sanders R, Vaupel Z, Erdogan M, Downes K. The operative treatment of displaced intra-articular calcaneal fractures (DIACFs): Long Term (10-20 years) Results in 108 Fractures using a Prognostic CT Classification. J Orthop Trauma 2014; 28: 551-63.

5. JL Labbe, O Peres, O Leclair, R Goulon, P Scemama, F Jourdel. Minimally invasive treatment of displaced intra-articular calcaneal fractures using the balloon kyphoplasty technique: preliminary study. Orthop Traumatol Surg Res 2013; 9: 829-36.

6. D Makki, HMAlnajjar, S Walkay, U Ramkumar, AJ Watson, PW Allen. Osteosynthesis of displaced intra-articular fractures of the calcaneum: a long-term review of 47 cases. J Bone Joint Surg Br 2010; 92: 693-700.

7. Potter MQ, Nunley J A. Long-term functional outcomes after operative treatment for intra-articular fractures of the calcaneus. J Bone Joint Surg Am 2009; 91: 1854-60.

8. Keener BJ, Sizensky JA. The anatomy of the calcaneus and surrounding structures. Foot Ankle Clin 2005; 10: 413-24. 